\title{
Development of TRINETRA : A Sensor Based Vision Enhancement System for Obstacle Detection on Railway Tracks
}

\author{
Anand Kumar Kyatsandra, R.K. Saket, Senior Member, IEEE, Sachin Kumar, Student Member, IEEE, \\ Kumari Sarita, Student Member, IEEE, Aanchal Singh S. Vardhan, and Akanksha Singh S. Vardhan
}

\begin{abstract}
The authors have developed a prototype, which promises easy passage for trains in unknown environments such as zero visibility situations, fog, smog, and heavy rain. The prototype is based upon the integration of a camera, Radio Detection and Ranging (RADAR), and Infrared (IR) Light Amplification by Stimulated Emission of Radiation (LASER). The camera used in the prototype catches a long-range view of the track and presents it live on a mini screen fixed in the loco pilot cabin. A combined short, mid, and long-range radar sensor system is used to detect obstacles continuously in loco pilot blind spots on the track, particularly for collision avoidance assistance at high speed. The present work proposes a long-range laser IR illuminator with a wide range of color and mono cameras to aid clear and precise monitoring in zero visibility conditions, which is fixed on the front portion/engine of the locomotive/engine. The prototype experimental results for $2 \mathrm{~m}-2 \mathrm{~km}$ distances have been performed on a live running train, which shows that the developed prototype tracks obstacles effectively during fog and smog conditions. The design concept, observation, prototype model, and other technical specifications have been presented, and satisfactory results were found.
\end{abstract}

Index Terms - Accidents, camera, illuminator, infrared laser, radar, reliability, TRINETRA.

\section{INTRODUCTION}

$\mathbf{T}$ RANSPORTATION systems like airways, railways, roadways, etc., have been considered as lifeline for humans. The transportation preferences are completely opted by humans based on their frequent availability, distance, and fare. Also, the preference may vary according to the particular country's population and GDP. Indian railway is one of the largest systems in the world, which includes more than $121 \times 10^{3} \mathrm{~km}$ of railway track with a route of $67 \times 10^{3} \mathrm{~km}$ and $7.3 \times 10^{3}$ modernized stations. Nearly $49 \%$ of the routes are electrified, and overall, 8 billion passengers and 1.2 billion tonnes of freight are recorded in 2017-2018. The revenue from freight and passengers of the Indian Railways is at the unbelievable stats of 16.5 billion USD and 6.9 billion USD, respectively.

The Indian railways are one of the world's largest railways in terms of 1.308 million employees who can handle 17 zones with 68 divisions. So, whenever such a large organization handles massive people, then reliability, safety, and security are the major concerns for management [1], [2]. Thus, a study on railway system reliability and safety has been performed, which depends upon errors related to the human operators [3].

Anand Kumar Kyatsandra is with the Division of Electrical Engineering, CSIR-National Aerospace Laboratories, Bangalore, Karnataka, India (email: anandkumarks1@gmail.com ).

R.K. Saket, Sachin Kumar, and Kumari Sarita are with the Department of Electrical Engineering, Indian Institute of Technology (Banaras Hindu University), Varanasi, Uttar Pradesh, 221005 India (email: rksaket.eee@iitbhu.ac.in, sachinkumar.rs.eee18@itbhu.ac.in, kumarisarita.rs.eee19@itbhu.ac.in).

Aanchal Singh S. Vardhan and Akanksha Singh S. Vardhan are with the Department of Electrical Engineering, Shri G.S. Institute of Technology and Science, Indore, Madhya Pradesh, 452003 India (email: aanchalvardhan123@gmail.com, aakankshasingh843@gmail.com).
Also, a real-time monitoring analysis has been established for railway system safety by implementing the cusp catastrophe model [4].

The railway systems lose thousands of USD due to a train delay, cancellation of trains, and mishaps during fog and smog conditions. Also, people lose their lives and time, which can not be tolerated at any cost [5]-[7]. In [8], the authors have provided a review of the literature on vision-based on-board obstacle detection and distance estimation in railways. The authors [9], [10] discussed the current developments and the performance of LIDAR, RADAR, vision cameras, ultrasonic sensors, and IR and review their capabilities and behaviour in a number of different situations: during daytime, at night, in extreme weather conditions. A collision risk prediction assessment has been performed to avoid train-train, or trainvehicle collisions [11]. Also, a vision-based traffic accident detection method was proposed to investigate the imbalance between regular traffic and traffic accident [12]-[14]. Further, a sliding window framework has been considered for detecting several moving objects by using a monocular moving camera [15], [16]. Because of this, a wide-angle camera-based practical back over warning system has been proposed [17] while, new planar object detection, and recognition method has been proposed on data association of light detection and ranging, and camera [18], [19]. The object detection process can also be performed using a rearview camera [20], [21], and a multiple-camera 3D object tracking system has been developed for traffic data collection at intersections [22], [23].

An Infrared (IR) emitted quantum cascade laser is used to illuminate these adverse environmental conditions properly. A vision-based traffic accident detection method was proposed 
to investigate the imbalance between normal traffic and traffic accident [12], [24]. A machine learning algorithm was proposed to recognize the road surfaces [25], [26]. In poor visibility conditions, 3D mobile laser scanning data have been utilized to detect side objects such as trains, light poles, and signpost [27]. Further, a sliding window framework has been considered for detecting several moving objects by using a monocular moving camera [15]. Because of this, a wideangle camera-based practical back over warning system has been proposed [17] while, new planar object detection, and recognition method has been proposed on data association of light detection and ranging, and camera [18], [19], [28]. The object detection process can also be performed using a rearview camera [20], and a multiple-camera 3D object tracking system has been developed for traffic data collection at intersections [22].

The Indian railway network is the most preferable and cheapest form of transport affordable by most of the society's classes; there is a huge demand for designing an efficient and reliable system, including signal interpretation, working conditions, and operations of the locomotives. Therefore, the present work has developed a prototype for avoiding accidents, which consists of a CMOS sensor camera, radar antenna, and IR laser illuminator. The design of a sensor using CMOS technology has been described, enabling the system's performance capability in terms of frames per second [29], [30]. Also, the calibration of an omnidirectional IR camera has been investigated for intelligent perception applications [31]. It has been recognized a need to understand and address the present challenges/issues related to loco-pilot comfort and visibility to prevent accidents on the tracks and make railway better, safer, reliable, and enhance pilots' situational awareness [32]. The train accidents can be avoided by equipping the present railway system with safety equipment. The study on the degree of reliability and accuracy becomes necessary where the safety and security fundamentals propose multiple sensor systems. The two salient concepts in the rail transport system are reliability and safety [33], [34].

The research work is proposed to provide a technological solution for the trains' standard performance during abnormal environmental conditions like fog, smog, zero-visibility condition, the obstacle on track when locos are driven in Long Hood Forward (LHF) and Short Hood Forward (SHF) Modes. The present work suggests an unconventional and dynamic concept to provide an experimental product for Indian railways to prevent accidents on the track. In order to maintain standard performance during zero visibility situations, impediments on the track, and locos run in LHF and SHF modes, the technique must perform better in fog. The article provides an innovative technological solution by developing a TRINETRA device for tackling the current operational issues encountered by the Indian railways' loco-pilots. The works described in the literature have not considered the abnormality, including fog, smog, and other bad weather conditions, as mentioned in Table I. The prototype device's development with its realtime experimental verification has not been observed in the literature. In contrast, the authors' main contributions to the research work are as follows.
TABLE I

AN OVERVIEW ON PREVIOUSLY PUBLISHED WORK

\begin{tabular}{|c|c|c|c|c|c|c|}
\hline & \multicolumn{6}{|c|}{ Parameters considered } \\
\hline Ref. & Visibility & $\begin{array}{l}\text { Train/Loco } \\
\text { speed }\end{array}$ & $\begin{array}{l}\text { Visual } \\
\text { distance }\end{array}$ & Fog & Obstacle & $\begin{array}{l}\text { Prototype } \\
\text { design }\end{array}$ \\
\hline [1] & & $\checkmark$ & $\checkmark$ & & & \\
\hline [35] & $\checkmark$ & & & $\checkmark$ & $\checkmark$ & $\checkmark$ \\
\hline [36] & $\checkmark$ & & & $\checkmark$ & $\checkmark$ & $\checkmark$ \\
\hline [37] & & $\checkmark$ & & & & \\
\hline [38] & $\checkmark$ & & $\checkmark$ & & $\checkmark$ & $\checkmark$ \\
\hline [39] & & $\checkmark$ & & & & \\
\hline$[40]$ & & $\checkmark$ & & & $\checkmark$ & 7 \\
\hline $\begin{array}{l}\text { Present } \\
\text { work }\end{array}$ & $\checkmark$ & $\checkmark$ & $\checkmark$ & $\checkmark$ & $\checkmark$ & $\checkmark$ \\
\hline
\end{tabular}

- Developed a prototype, namely, TRINETRA.

- TRINETRA has been implemented and tested experimentally.

- The results obtained by considering different cameras for various distances.

- Live running train has been considered for proper validations.

The accomplishment of the mentioned contributions, the article has been organized as follows. Section I presents Indian railway networks and fundamental problems related to train accidents in Indian railways. An overview of the casualties in Indian railways and the requirement of development of TRINETRA to prevent train cancellations and accidents during the foggy sessions have been described in Section II. Essential aspects of design concepts of TRINETRA have been illustrated in the Section III. Section IV presents a brief model arrangement methodology of system components for the reliable operation of the developed TRINETRA. The experimental observations are included in Section V. The overall conclusion and future research plan are described in Section VI. The flow chart of the present research work is described in Fig. 1.

\section{AN OVERVIEW OF ACCIDENTS IN INDIAN RAILWAYS}

The railway accidents in India are due to the collision, derailments, level crossing, and fire in trains. Derailment is one of the major causes due to which mishaps occur, and the dense fog in winter is also aided to the accidents at level crossings. During India's winter season (November-January), the mist is quite regular, with temperatures approximately 34 degrees to 10-12 degrees, and the fog sometimes converts to smog in some polluted places. Either fog or smog may lead to the zero-visibility condition, which depends on the concentration of droplets and this condition leads to multiple collisions of road vehicles and trains. Smog is originally named for the mixture of fog and smoke in the air. The number and type of accidents, accidents per million $\mathrm{km}$ run, number of casualties, casualties per million passengers carried, and cases of railway accidents are described in the upcoming subsections. So, to save lives, time, and economy, the present work proposes to equip the Indian railway locomotives with a TRINETRA, which is treated as an anti-accident system to stop derailments, train collisions, and unmanned crossing accidents. The proposed technology is based on a radar-based device that alerts loco pilots whenever an obstacle comes on 


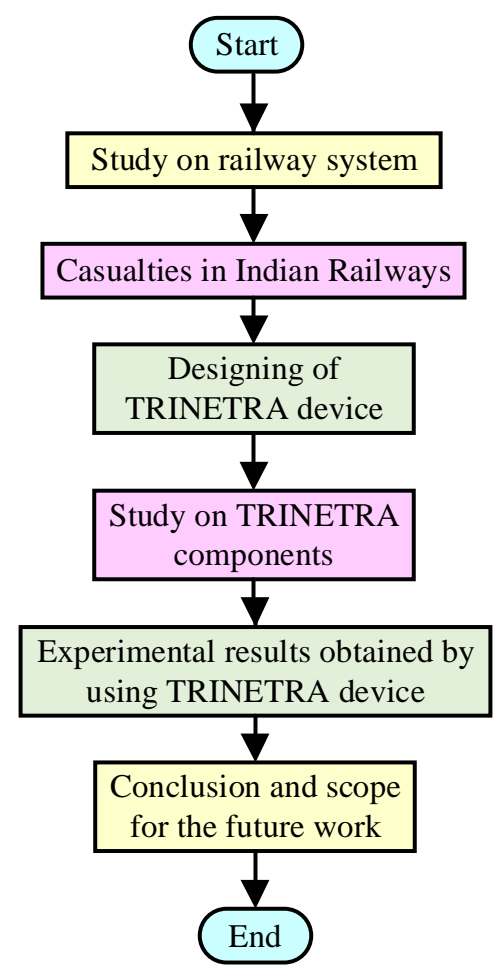

Fig. 1. Flow of the present research work.

the railway track and prevents a collision or any other accident. The developed TRINETRA will be more useful in foggy nights and smog conditions when drivers continuously look outside the locomotive to assess the weather conditions.

\section{A. Number and type of accidents}

The $90 \%$ of railway accidents in India are due to derailments and accidents at level crossings during fog and smog conditions, and the remaining ten percent of accidents are due to rail collisions. The number of casualties in Indian railways by type from 2011 to 2020 are listed in using Table II. The graphical representation of railways accidents during 2011 to 2020 is described in Figure 2. The reason of accidents due to collision and level crossing is fog and smog.

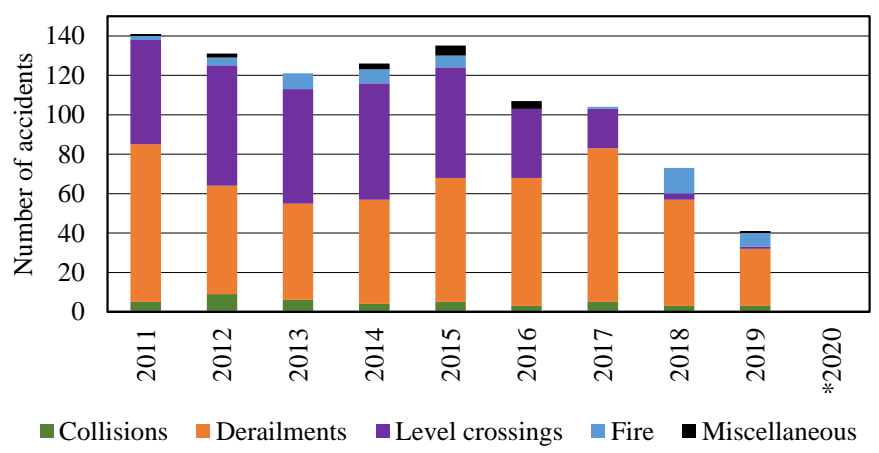

Fig. 2. Train accidents between 2011 to 2020 .
TABLE ॥

NUMBER OF TRAIN ACCIDENTS ACCORDING TO THEIR TYPES (2011 TO 2020)

\begin{tabular}{llllll}
\hline \hline Year & Collisions & \multicolumn{2}{c}{$\begin{array}{c}\text { Derailments Level } \\
\text { crossings }\end{array}$} & Fire & Misc. \\
\hline \hline 2011 & 5 & 80 & 53 & 2 & 1 \\
2012 & 9 & 55 & 61 & 4 & 2 \\
2013 & 6 & 49 & 58 & 8 & NR \\
2014 & 4 & 53 & 59 & 7 & 3 \\
2015 & 5 & 63 & 56 & 6 & 5 \\
2016 & 3 & 65 & 35 & 0 & 4 \\
2017 & 5 & 78 & 20 & 1 & 0 \\
2018 & 3 & 54 & 3 & 13 & 0 \\
2019 & 3 & 29 & 1 & 7 & 1 \\
$* 2020$ & - & - & - & - & - \\
\hline \hline
\end{tabular}

$\mathrm{NR}=$ not reported, ${ }^{*}$ Pandemic year

\section{B. Train accidents between 2010-11 and 2017-18}

The Indian railway carries more passengers each year in terms of number per $\mathrm{km}$. The number is increased from 2.1 million $\mathrm{km}$ to 11.5 million $\mathrm{km}$ from 1980-81 to 2017-18. The number of train accidents per million $\mathrm{km}$ is decreased steadily from 2009-2010 to 2016-2017 and then suddenly increases in 2017-2018, as illustrated in Table III. The train accidents are well shown graphically in Figure 3. Overall, a trend of tremendous decrease in train accidents is noticed but still a significant concern if a single casualty occurs.

TABLE III

TRAIN ACCIDENTS PER MILLION KMS RUN AND NUMBER OF CASUALTIES PER MILLION PASSENGERS (2011 TO 2020)

\begin{tabular}{ccc}
\hline \hline Year & accidents per million $\mathrm{km}$ & casualties per million passengers \\
\hline \hline 2011 & 0.14 & 0.088 \\
2012 & 0.12 & 0.078 \\
2013 & 0.11 & 0.083 \\
2014 & 0.10 & 0.039 \\
2015 & 0.11 & 0.020 \\
2016 & 0.10 & 0.050 \\
2017 & 0.09 & 0.020 \\
2018 & 0.06 & 0.070 \\
2019 & 0.02 & 0 \\
$* 2020$ & - & - \\
\hline \hline
\end{tabular}

*Pandemic year

\section{Casualties per million passengers carried}

As shown in Table IV, the per million passenger casualties are decreased in 2017-2018 compared to 2010-2011. The originating number of passengers are nearly 3600 million in 1980-1981 and increased to 8200 million in 2014-2015. The deaths per million passengers carried by railways during 200910 to 2017-18 are shown in Figure 4.

In any train accident, some casualties occur either in dead or injury form. So, Figure 4 shows the number of casualties per million $\mathrm{km}$ run, and it is concluded that casualties are increased and then decreased in 2017-2018. It is also seen that where the ratio of killed and injured is approaching, one leads to fatal accidents. 


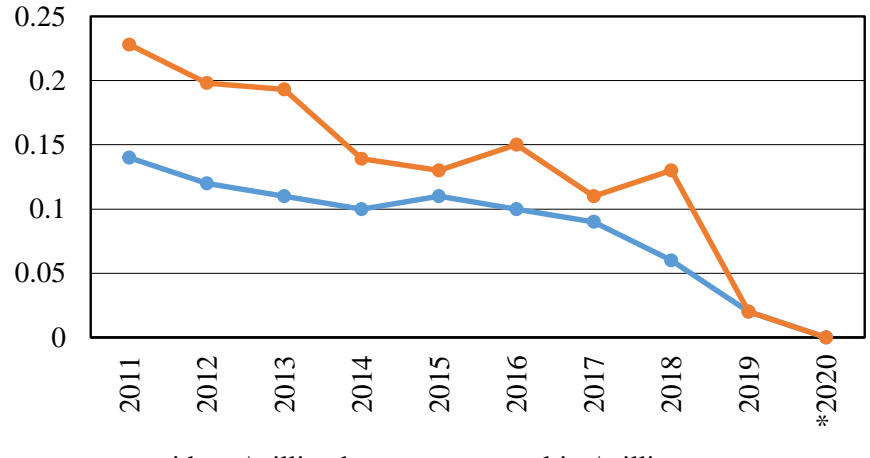

Fig. 3. Accidents per million $\mathrm{km}$ run and casualties per million passengers carried.

TABLE IV

Number OF CASUALTIES (2011 TO 2020)

\begin{tabular}{ccc}
\hline \hline Year & Killed & Injured \\
\hline \hline 2011 & 235 & 358 \\
2012 & 100 & 586 \\
2013 & 60 & 270 \\
2014 & 42 & 94 \\
2015 & 118 & 340 \\
2016 & 40 & 126 \\
2017 & 195 & 346 \\
2018 & 28 & 184 \\
2019 & 0 & 156 \\
$* 2020$ & - & - \\
\hline \hline
\end{tabular}

$\mathrm{NR}=$ not reported, ${ }^{*}$ Pandemic year

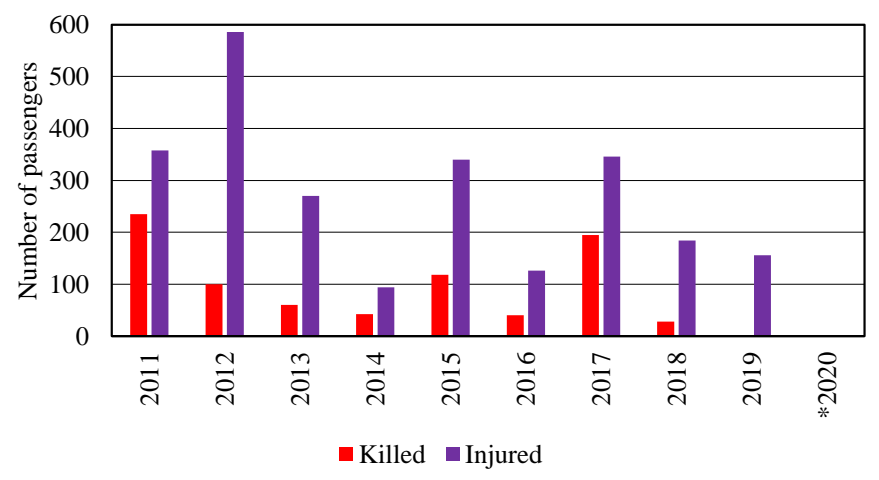

Fig. 4. Number of casualties in train accidents.

\section{Cause of accidents in Indian railways}

The development of TRINETRA technology is due to the various causes of train accidents where it is found that maximum accidents occur due to human mistakes (87\%), as shown in Table V. Other than this, equipment failure, sabotage, and unexpected failure are the leading causes of train mishaps, as described in Figure 4. The factors like fog and smog may invoke a few of the losses.

In innovative TRINETRA, a radar-based device is used to alert the loco pilot to prevent casualties due to accidents. This proposed system is more useful in India during the foggy and smog conditions at night to assess the atmospheric conditions. To tab the signals up to $1-2 \mathrm{~km}$ distance, the developed TRINETRA technique uses infra-red and displays
TABLE V

NUMBER OF TRAIN ACCIDENTS ACCORDING TO THEIR CAUSES (2011 TO 2020)

\begin{tabular}{lllllll}
\hline \hline Year & Railway staff & $\begin{array}{l}\text { Other } \\
\text { than } \\
\text { railway } \\
\text { staff }\end{array}$ & Equipment & Sabotage & Incidental & Other \\
\hline \hline 2011 & 56 & 57 & 5 & 16 & 4 & \\
2012 & 52 & 63 & 5 & 6 & 3 & 3 \\
2013 & 45 & 59 & 6 & 3 & 7 & 1 \\
2014 & 50 & 55 & 3 & 4 & 4 & 1 \\
2015 & 60 & 58 & 4 & 3 & 8 & 2 \\
2016 & 55 & 38 & 2 & 1 & 9 & 2 \\
2017 & 64 & 22 & 2 & 2 & 7 & 7 \\
2018 & 44 & 18 & 2 & 2 & 5 & 2 \\
2019 & 38 & 17 & 3 & 0 & 3 & 3 \\
$* 2020$ & - & - & - & - & - & - \\
\hline \hline
\end{tabular}

${ }^{*}$ Pandemic year

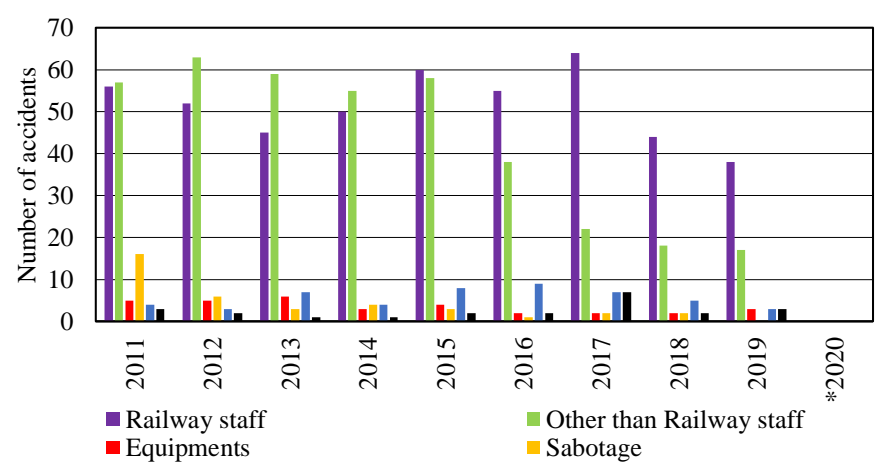

Fig. 5. Number of train accidents with their causes.

the actual information on the screen, which is fitted inside the locomotive. The screen information suggests the driver stop the train within a prescribed time period.

The proposed system easily senses the presence of any animal, a boulder lying, or any uprooted tree on the railway tracks. If any vehicle or tree has broken down or any animal is present on the rail tracks, the developed system will notice them well in advance. The development of this device will be a part of Indian railways to avoid train accidents. In an attempt to avoid train accidents, Indian Railways should initiate a process to launch the TRINETRA system. This device will alert the drivers of any physical obstruction on railway tracks ahead and thus avert accidents. This will be useful during nights and in foggy conditions and the drivers need not to look outside the locomotive to assess the condition. The only drawback is that it can not visualize the objects coming just behind the curves.

\section{DESIGN CONCEPT OF TRINETRA DEVICE}

The present work aims to design the TRINETRA to prevent the above severe accidents during the winter season (November to January) in India to make the railways a zerotolerance zone for accidents. The suggestion of this research work is to install an automatic signaling system, anti-collision devices, and train protection and warning system in all trains in the coming years to avoid accidents in India. The proposed 
technologies of TRINETRA will help the Indian railways to prevent any accident, and there will be no railway accidents in the future. The experimental TRINETRA is offered with three technological components and combinations, as provided in Figure 6. The developed prototype TRINETRA system

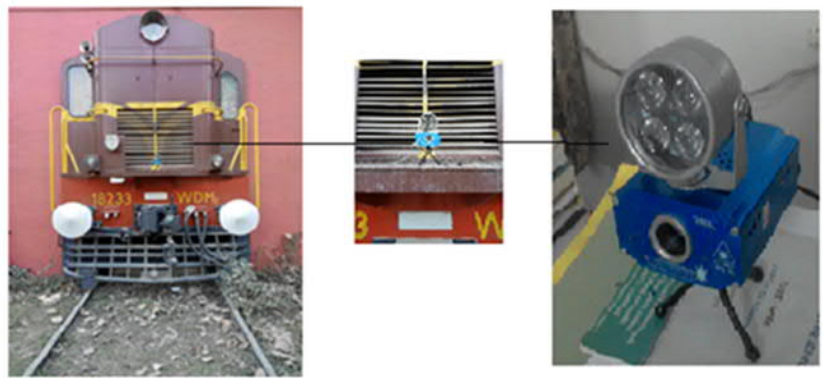

Fig. 6. Developed prototype TRINETRA system fixed on the front portion of the locomotive engine.

uses bullet camera + lens: IR cut filter (color to black) 1.2 megapixel Complementary Metal Oxide Semiconductor (CMOS) sensor + the electric zoom lenses with Fixed Focal Length (FFL) of $3.5 \mathrm{~mm}$ to $100 \mathrm{~mm}$ built-in digital HD module to image up to 1080P. Brief descriptions of proposed design components like thermal camera, obstacles sensing radar, and laser infrared illuminator are given below.

\section{A. The optical camera system}

It is necessary to incorporate a quality high definition night vision camera in TRINETRA, as shown in Figure 7. The experimental camera is a Pan-Tilt-Zoom Internet Protocol (PTZ IP) type with high resolution, long-distance lens, and infrared illuminator to identify the object details up to $2 \mathrm{~km}$. The illuminator with a $2000 \mathrm{~m}$ range and the security system is integrated with the camera, and the TRINETRA setup is attached to the Indian railway network. The thermal imaging camera is used for night vision in bad weather conditions like fog, and also the optical zoom camera with laser technology provides details of the Indian railway tracks. According to the availability of models, the list is illustrated in Table VI.

\section{$B$. The obstacle sensing radar system}

The requirement of a hindrance sensing radar system for the Indian railway is important to enhance lives' security and safety. The radar system of high resolution provides enough details of obstacles; hence it is compatible with Indian railway applications. An obstacle sensing radar system for a railway crossing application has been implemented to operate trains normally. The combined short, mid, and long-range radar antenna chipset for $76 \mathrm{GHz}$ to $77 \mathrm{GHz}$ Frequency-Modulated Continuous-Wave (FMCW) radar sensor system is used in this experiment. A phased array receiver module at $77 \mathrm{GHz}$ is needed to design and manufacture to achieve the ray beam steering capacity. The comparison between the passive element antenna array and measure gains of phased array receiver is made for performance enhancement of system [42].
TABLE VI

DAY AND NIGHT VISION PTZ IP CAMERA SYSTEM

\begin{tabular}{|c|c|c|c|}
\hline $\begin{array}{l}\text { S. } \\
\text { No. }\end{array}$ & Model & Range & Lens \\
\hline 1. & $\begin{array}{l}\text { TVIP-PHX- } \\
\text { 640-30X- } \\
\text { 100HD }\end{array}$ & $\begin{array}{l}\text { Detection: Day: over } \\
5.950 \mathrm{~km} \text {, Night: } 1 \\
\text { km, Recognition Day: } \\
1.6 \mathrm{Km} \text {, Night: } 0.309 \\
\text { Km, Identification: } \\
\text { Day: } 0.793 \mathrm{~km} \text {, } \\
\text { Night: } 0.153 \mathrm{~km}\end{array}$ & $\begin{array}{l}\text { Optical zoom: } \\
37 X \text { zoom } \\
\text { lens maximum } \\
\text { zoom to } 12.9 \\
\text { cm, Thermal } \\
\text { lens: Fixed } 10 \\
\mathrm{~cm}\end{array}$ \\
\hline 2. & $\begin{array}{l}\text { TVIP-SGMA- } \\
\text { 1000M- } \\
\text { 500mm-HD }\end{array}$ & $\begin{array}{l}\text { Detection: Day: } 22 \\
\text { km, Night: } 1 \mathrm{~km} \text {, } \\
\text { Recognition: Day: } 5.9 \\
\text { km, Night: } 0.998 \mathrm{~km} \\
\text { Identification: Day: } \\
2.9 \mathrm{~km} \text {, Night: } 0.998 \\
\text { km }\end{array}$ & $\begin{array}{l}\text { Optical zoom: } \\
33 \mathrm{X} \text { remote } \\
\text { zoom lens, } 2 \text { to } \\
50 \mathrm{~cm}\end{array}$ \\
\hline 3. & $\begin{array}{l}\text { TVIP-OPTH- } \\
\text { 2000M-2000- } \\
\text { HD }\end{array}$ & $\begin{array}{l}\text { Detection: } \\
66 \quad \mathrm{~km}, \quad \text { Night } \\
\text { (using laser): } \\
\text { km, Recognition: } \\
\text { Day: } 17.7 \mathrm{~km} \text {, Night } \\
\text { (using laser): } 2 \mathrm{~km} \text {, } \\
\text { Identification: Day: } \\
8.8 \mathrm{~km} \text {, Night (using } \\
\text { laser): } 2 \mathrm{~km}\end{array}$ & $\begin{array}{l}\text { Optical Zoom: } \\
125 \mathrm{X} \text { zoom } \\
\text { lens, } 1.6 \mathrm{~cm} \text { to } \\
200 \mathrm{~cm} \text { remote } \\
\text { zoomlens. } \\
\text { Thermal lens: } \\
3.5-15.5 \mathrm{~cm} \\
\text { remote zoom } \\
\text { lens }\end{array}$ \\
\hline
\end{tabular}

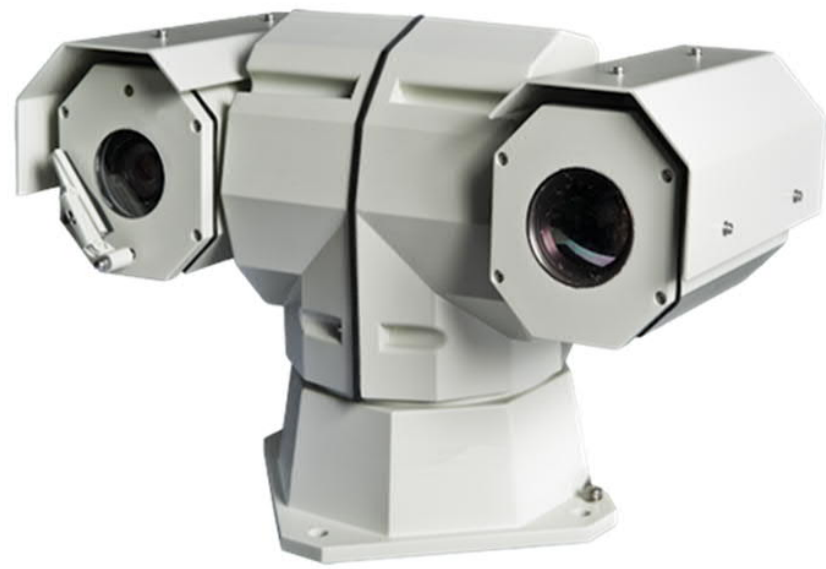

Fig. 7. PTZ IP camera.

\section{The laser infrared illuminator}

A long-range laser infrared illuminator equipped with a camera for use with a wide range of color and mono cameras to aid clear and precise monitoring in the dark. It has long safely dispersed the beam at a wide $4^{0}$ angle to light up a huge area of $400 \mathrm{~m}^{2}$ at a $300 \mathrm{~m}$ range, as shown in Figure 8. A 3D outdoor scene scanner has been presented to acquire km deep scenes in night conditions [43]. Its imaging system includes a low-cost pulsed laser illuminator and a Charge Coupled Device (CCD) camera equipped with a light intensifier as it is possible to get portions of the scene at a certain distance by accurately synchronizing the camera and illuminator. Hence, a long-distance scanning with smaller portions allows camera adjustment concerning the accuracy and enhanced range. The image pixel intensities produce active image systems that are 
varied with the square of the distance and limit of image sensors.

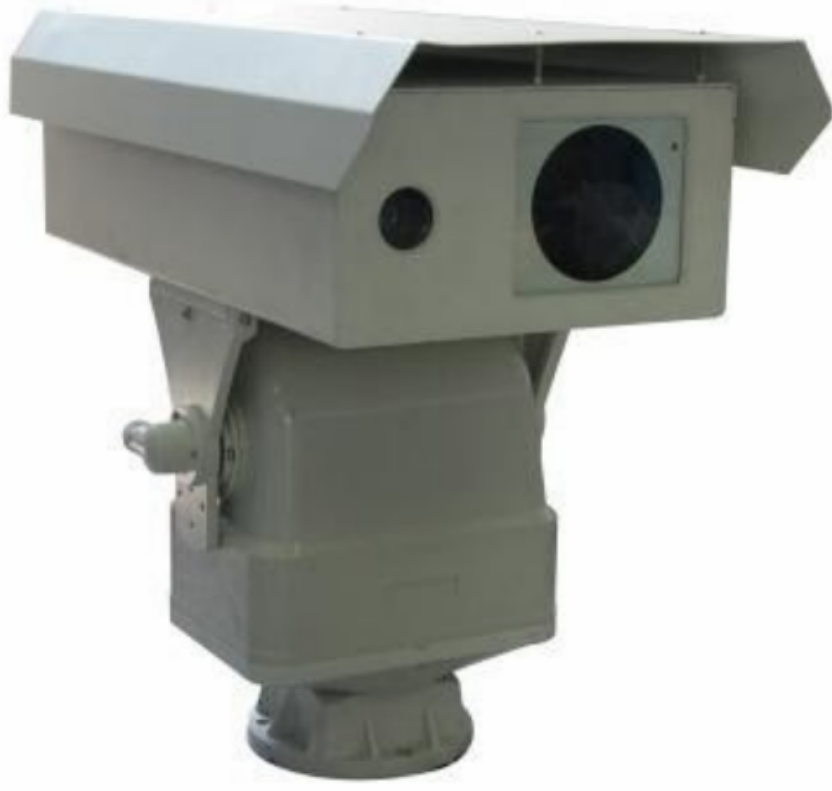

Fig. 8. Long range laser infrared illuminator.

The concept of TRINETRA, an indigenous cost-effective camera equipped with laser rays and display unit, is an outcome of our research efforts to address the current operational visibility issues faced by the loco pilots of Indian railways during abnormal weather conditions, as shown in Figure 9. According to outer visibility, the train speed has been considered, as described in Table VII. This approach is especially applicable during the fog, smog, and rain and locos driven in LHF and SHF Modes, as described in Figures 10 and 11 .

TABLE VII

VISIBILITY VS TRAIN SPEED CONSIDERED FOR EXPERIMENT

\begin{tabular}{lll}
\hline \hline S.No. & Visibility & Train speed restriction \\
\hline \hline 1 & $600 \mathrm{~m}$ or above & no speed restriction \\
2 & $<600 \mathrm{~m}$ but $\geq 540$ & $90 \mathrm{kmph}$ \\
3 & $<540 \mathrm{~m}$ but $\geq 450$ & $75 \mathrm{kmph}$ \\
4 & $<450 \mathrm{~m}$ but $\geq 360$ & $60 \mathrm{kmph}$ \\
5 & $<360 \mathrm{~m}$ but $\geq 270$ & $45 \mathrm{kmph}$ \\
6 & $<270 \mathrm{~m}$ but $\geq 180$ & $30 \mathrm{kmph}$ \\
7 & $<180 \mathrm{~m}$ but $\geq 120$ & $20 \mathrm{kmph}$ \\
8 & $<120 \mathrm{~m}$ & $10 \mathrm{kmph}$ \\
\hline
\end{tabular}

\section{INSTALLATION OF TRINETRA COMPONENTS}

Equipped with a CMOS sensor camera, radar trans-receive antenna, and IR laser illuminator integration is known as TRINETRA, a hybrid system is fixed on the front portion of the locomotive engine in Figure 12. It will catch a longrange view of the track efficiently and present it live on a mini

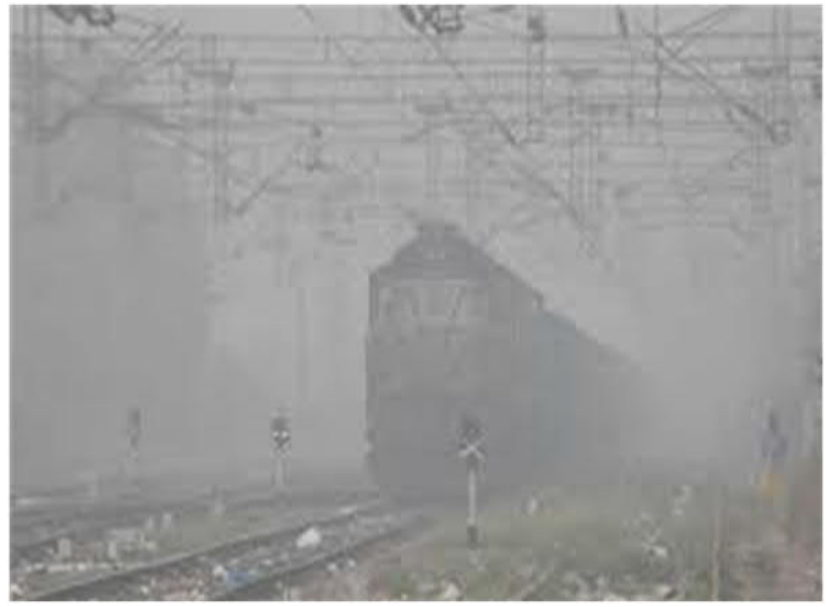

Fig. 9. Poor visibility due to odd weather conditions.

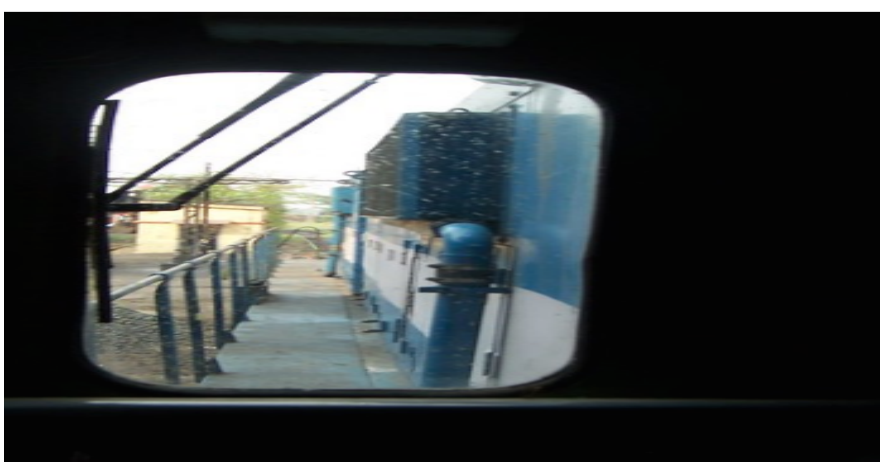

Fig. 10. Locos driven in Long Hood Forward (LHF).

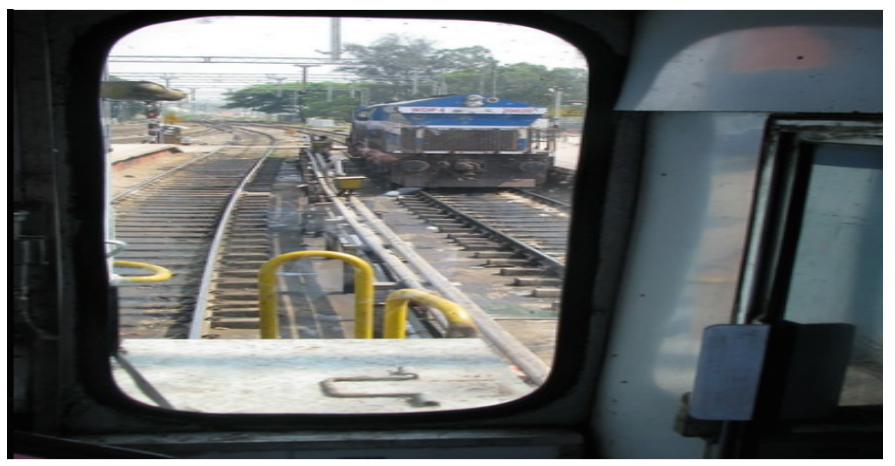

Fig. 11. Locos driven in Short Hood Forward (SHF).

screen fixed at the loco pilot cabin, as described in Figure 13. Infrared (IR) laser illuminator will stay OFF when there are enough light sources, such as daytime and typical weather conditions. The Opto light sensor will trigger the illuminator during poor weather conditions such as fog, smog, and heavy rain.

Radar detects the distance of obstacles located at the engine's locomotive and sends an early warning and indication to loco pilots in the mini screen arranged in the cabin before a collision occurs. 


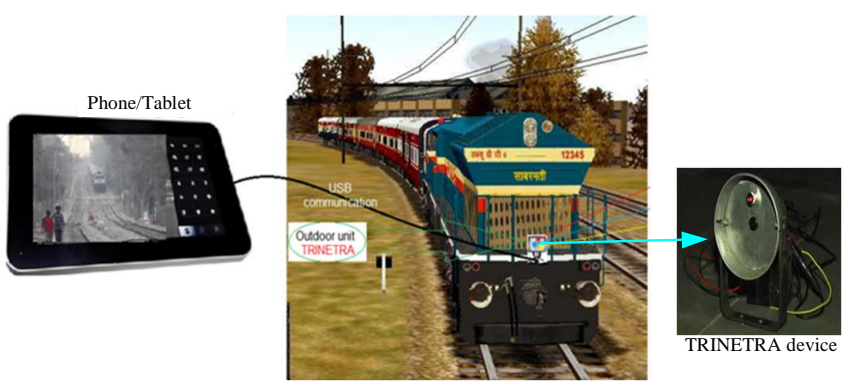

Fig. 12. Camera, Radar, and IR laser illuminator integration model of TRINETRA.

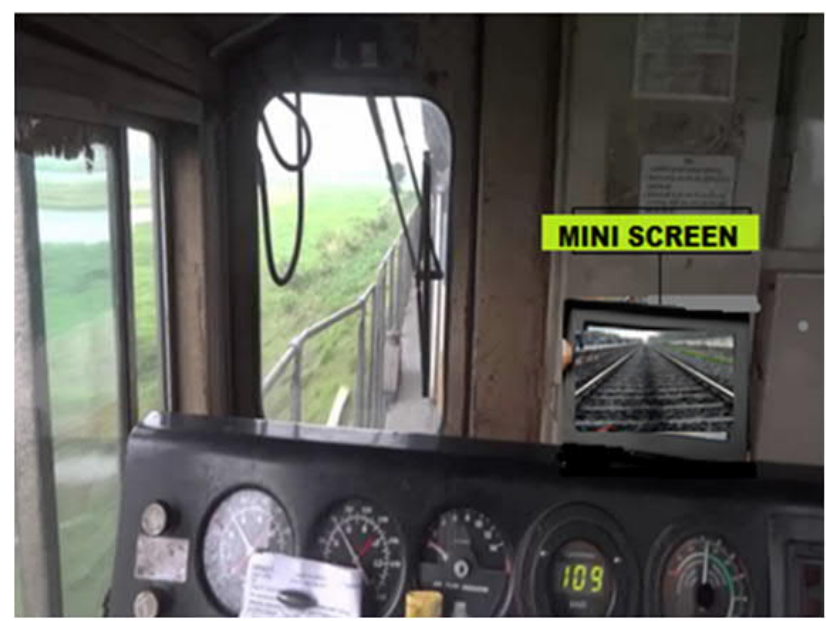

Fig. 13. Mini screens fixed on locos pilot cabin.

\section{EXPERIMENTAL OBSERVATIONS AND RESULTS}

The TRINETRA system is proposed to fix on the front portion of the engine/locomotive. It catches a long-range view of the track efficiently and presents it live on a mini-screen set at the loco pilots' cabin. The train pilots can see the long range of tracks on screen. The tracks can be seen clearly using a camera-radar-laser combination. The observations related to the designed TRINETRA device have been made experimentally, illustrated in Tables VIII to Table XI. The TRINETRA device has been implemented on train number 12229, namely, Lucknow-New Delhi, described in Figure 14. The developed TRINETRA technique uses infra-red and displays the actual information on the screen, fitted inside the locomotive.

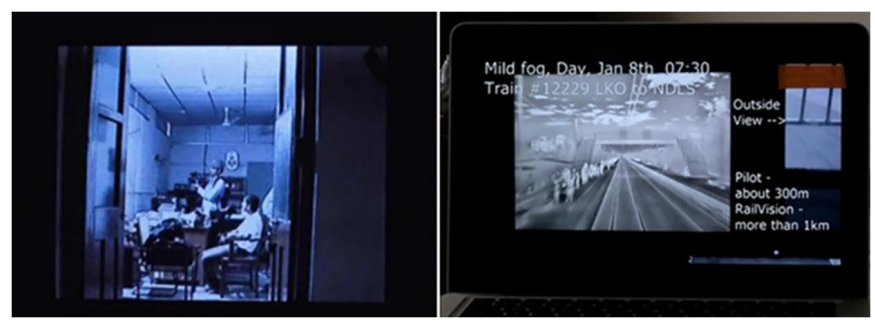

Fig. 14. Experimental implementation of TRINETRA.

\section{A. Experiment No. 1}

The obtained results from the first experiment on designed TRINETRA indicate that the 1.2 megapixel CCD camera, infrared $(810 \mathrm{~nm}) 20 \mathrm{~mW}$ diode laser, 4.3 inch Thin Film Transistor (TFT) Liquid Crystal Display (LCD) color monitor can catch and present the view up to $2 \mathrm{~m}$ distance in zero visibility situation. Obtained results from the first experiment are illustrated in Table VIII.

TABLE VIII

RESULTS OBTAINED IN EXPERIMENT NO. 1

\begin{tabular}{ll}
\hline \hline CCD camera & 1.2 megapixel \\
Infrared & $810 \mathrm{~nm}$ \\
Diode laser & $20 \mathrm{~mW}$ \\
TFT LCD color monitor & $4.3 \mathrm{inch}$ \\
Night view distance & $2 \mathrm{~m}$ \\
\hline \hline
\end{tabular}

\section{B. Experiment No. 2}

The obtained results from the second experiment on TRINETRA indicate that the 10 megapixel HD CCD camera, infrared $(810 \mathrm{~nm}) 20 \mathrm{~mW}$ diode laser, 4.3 inch TFT LCD color monitor is able to catch and present the view up to $200 \mathrm{~m}$ distance in zero visibility situation. Obtained results from the second experiment are shown in Table IX.

TABLE IX

RESULTS OBTAINED IN EXPERIMENT NO. 2

\begin{tabular}{ll}
\hline \hline HD CCD camera & 10 megapixel \\
Infrared & $810 \mathrm{~nm}$ \\
Diode laser & $20 \mathrm{~mW}$ \\
TFT LCD color monitor & $4.3 \mathrm{inch}$ \\
Night view distance & $200 \mathrm{~m}$ \\
\hline \hline
\end{tabular}

\section{Experiment No. 3}

The obtained results from the third experiment on innovative TRINETRA indicate that the TVIP SGMA HD camera, infrared $(810 \mathrm{~nm}) 20 \mathrm{~mW}$ diode laser, 4.3 inch TFT LCD color monitor is able to catch and present the view up to 998 $\mathrm{m}$ distance in zero visibility situation. The obtained results from the third experiment are illustrated in Table X.

TABLE X

RESULTS OBTAINED IN EXPERIMENT NO. 3

\begin{tabular}{lll}
\hline \hline HD TVIP SGMA 1000M, 500 & Optical zoom: & $33 \mathrm{X}$, \\
mm camera & $20-500 \mathrm{~mm}$ & \\
Infrared & $810 \mathrm{~nm}$ & \\
Diode laser & $20 \mathrm{~mW}$ & \\
TFT LCD color monitor & $4.3 \mathrm{inch}$ \\
Night view distance & $998 \mathrm{~m}$ \\
\hline \hline
\end{tabular}




\section{Experiment No. 4}

The obtained results from the fourth experiment on developed TRINETRA represents that the TVIP OPTH HD camera, infrared $(810 \mathrm{~nm}) 20 \mathrm{~mW}$ diode laser, 4.3 inch TFT LCD color monitor can catch and present the view up to $2000 \mathrm{~m}$ distance in zero visibility situation. The obtained results from the fourth experiment are illustrated in Table XI.

TABLE XI

RESULTS OBTAINED IN EXPERIMENT NO. 4

\begin{tabular}{ll}
\hline \hline HD TVIP OPTH 2000M, 2000 & Optical zoom: 125X, \\
mm camera & $35-155 \mathrm{~mm}$ \\
Infrared & $810 \mathrm{~nm}$ \\
Diode laser & $20 \mathrm{~mW}$ \\
TFT LCD color monitor & $4.3 \mathrm{inch}$ \\
Night view distance & $2 \mathrm{~km}$ \\
\hline \hline
\end{tabular}

\section{E. Experiment No. 5 \& 6}

The obtained results from the fifth experiment on developed TRINETRA represents that the PHX-39X-TI $1920 \times 1080 \mathrm{HD}$ camera, can catch and present the view up to $2.4 \mathrm{~km}$ human detection \& $7.3 \mathrm{~km}$ vehicle detection in zero visibility situation with thermal imager and lens. Increasing the Mega Pixel helps in increasing the visibility range. The obtained results from the fifth and sixth experiments are illustrated in Tables XII and XIII respectively.

It is observed that using better resolution camera with higher Mega Pixel helps in enhancing the visibility to a larger range. This is working as a third eye for the train to see the tracks clearly.

TABLE XII

RESULTS OBTAINED IN EXPERIMENT NO. 5

\begin{tabular}{ll}
\hline \hline PHX-39X-TI (ONVIF IP PTZ & Optical zoom: 39X, 8-315mm, \\
system) 2400M, 2000 mm lens & $1920 \times 1080 \mathrm{HD}$ \\
Spectral range & $7,000-14,000 \mathrm{~nm}$ \\
Power consumption & Max $80 \mathrm{~W}$ \\
Visible Sensor & $2 \mathrm{MP} 1 / 2.8$ \\
View distance & $2.4 \mathrm{~km}$ human detection \& 7.3 \\
& $\mathrm{~km}$ vehicle detection \\
\hline \hline
\end{tabular}

PHX $=$ Phoenix, TI $=$ Thermal Imager, ONVIF $=$ Open Network Video Interface Forum

TABLE XIII

RESULTS OBTAINED IN EXPERIMENT NO. 6

\begin{tabular}{ll}
\hline \hline PHX-39X-TI (ONVIF IP PTZ & Optical zoom: 39X, 30-180mm, \\
system) 2400M, 2000 mm lens & $1920 \times 1080 \mathrm{HD}$ \\
Spectral range & $7,000-14,000 \mathrm{~nm}$ \\
Power consumption & Max 90 W \\
Visible Sensor & $5 \mathrm{MP} 1 / 2.8$ \\
View distance & $6.9 \mathrm{~km}$ human detection \& 12.6 \\
& $\mathrm{~km}$ vehicle detection \\
\hline \hline
\end{tabular}

\section{CONCLUSION}

The developed TRINETRA device has been dedicated to Indian railways after successful real-time experiments on running train. The railway system can continue to operate normally in foggy conditions and zero-visibility situations like smog, heavy rains, and storms. After performing a rigorous survey, it was concluded that railway accidents are very prone to abnormal environmental conditions. Thus, the present work has performed real-time experiments to verify the usability of the developed prototype. During the real-time experiments, it was found that the device performed better for distances up to $2 \mathrm{~km}$.

TRINETRA provides the predictive detection of obstacles on tracks and collision warning to loco-pilots has driven in long hood forward and short hood forward modes. The output would automatically keep loco-pilots at a distance from the locomotive in front and contribute to preventing accidents on the tracks by identifying potentially dangerous situations and responding accordingly.

The present work aims to install an automatic signaling system, an anti-collision device, and a warning system to avoid train accidents. Further, the developed prototype can also be helpful as a surveillance technology during these abnormal conditions. The proposed technologies of TRINETRA would help the Indian railways in preventing the accidents, and there would be no related casualties in the future. Further, the device can be improved in terms of distance and visibility, and the economic aspects can be considered the future research scopes.

\section{REFERENCES}

[1] Y. Zhang, H. Wang, T. Yuan, J. Lv, and T. Xu, "Hybrid online safety observer for ctcs-3 train control system on-board equipment," IEEE Transactions on Intelligent Transportation Systems, vol. 20, no. 3, pp. 925-934, 2018.

[2] H. Zhao, X. Dai, L. Ding, D. Cui, J. Ding, and T. Chai, "Resilient cooperative control for high-speed trains under denial-of-service attacks," IEEE Transactions on Vehicular Technology, 2021.

[3] A. Ferlin, S. Qiu, P. Bon, M. Sallak, S. C. Dutilleul, W. Schön, and Z. Cherfi-Boulanger, "An automated method for the study of human reliability in railway supervision systems," IEEE Transactions on Intelligent Transportation Systems, vol. 19, no. 10, pp. 3360-3375, 2018.

[4] Y. Wang, S. Y. M. Liu, L. Cho, K. Lee, and H. Tam, "A method of railway system safety analysis based on cusp catastrophe model," Accident Analysis \& Prevention, vol. 151, p. 105935, 2021.

[5] K. Anand Kumar and R. Saket, "Invention of trinetra: The third eye to prevent railway accidents," Patent Application Number: 201641045006, Indian Patent, CBR No.: 36449, 2016.

[6] W. Hao, B. Moghimi, X. Yang, C. Kamga, Y. Wang, L. Xiao, and Z. Liu, "Effects of foggy conditions on driver injury levels in us highway-rail grade crossing accidents," Case studies on transport policy, vol. 5, no. 4, pp. 627-633, 2017.

[7] S. Zhang, T. Tang, and J. Liu, "A hazard analysis approach for the sotif in intelligent railway driving assistance systems using stpa and complex network," Applied Sciences, vol. 11, no. 16, p. 7714, 2021.

[8] D. Ristić-Durrant, M. Franke, and K. Michels, "A review of visionbased on-board obstacle detection and distance estimation in railways," Sensors, vol. 21, no. 10, p. 3452, 2021.

[9] X. Yu and M. Marinov, "A study on recent developments and issues with obstacle detection systems for automated vehicles," Sustainability, vol. 12, no. 8, p. 3281, 2020.

[10] F. C. Nemtanu and M. Marinov, "Digital railway: Trends and innovative approaches," in Sustainable Rail Transport. Springer, 2019, pp. $257-$ 268 
[11] V. Singhal, S. Jain, D. Anand, A. Singh, S. Verma, J. J. Rodrigues, N. Z. Jhanjhi, U. Ghosh, O. Jo, C. Iwendi et al., "Artificial intelligence enabled road vehicle-train collision risk assessment framework for unmanned railway level crossings," IEEE Access, vol. 8, pp. 113 790-113 806, 2020.

[12] Y. Yu, M. Xu, and J. Gu, "Vision-based traffic accident detection using sparse spatio-temporal features and weighted extreme learning machine," IET Intelligent Transport Systems, vol. 13, no. 9, pp. 1417-1428, 2019

[13] B. Sabu and M. Marinov, "An obstacle detection system for freight yards," IF Ingegneria Ferroviaria, vol. 73, no. 6, p. 539, 2018.

[14] M. Dent and M. Marinov, "Introducing automated obstacle detection to british level crossings," in Sustainable Rail Transport. Springer, 2019, pp. $37-80$.

[15] S. Minaeian, J. Liu, and Y.-J. Son, "Effective and efficient detection of moving targets from a uav's camera," IEEE transactions on intelligent transportation systems, vol. 19, no. 2, pp. 497-506, 2018.

[16] C. M. Parameshwara, N. J. Sanket, C. D. Singh, C. Fermüller, and Y. Aloimonos, "0-mms: Zero-shot multi-motion segmentation with a monocular event camera," in 2021 IEEE International Conference on Robotics and Automation (ICRA). IEEE, 2021, pp. 9594-9600.

[17] J. K. Suhr and H. G. Jung, "Rearview camera-based backover warning system exploiting a combination of pose-specific pedestrian recognitions," IEEE transactions on intelligent transportation systems, vol. 19, no. 4, pp. 1122-1129, 2017.

[18] Z. Deng and L. Zhou, "Detection and recognition of traffic planar objects using colorized laser scan and perspective distortion rectification," IEEE Transactions on Intelligent Transportation Systems, vol. 19, no. 5, pp. 1485-1495, 2017.

[19] Z. Guo, B. Cai, W. Jiang, and J. Wang, "Feature-based detection and classification of moving objects using lidar sensor," IET Intelligent Transport Systems, vol. 13, no. 7, pp. 1088-1096, 2019.

[20] J. K. Suhr and H. G. Jung, "Rearview camera-based stixel generation for backing crash prevention," IEEE Transactions on Intelligent Transportation Systems, vol. 21, no. 1, pp. 117-134, 2019.

[21] Y. J. Lee, J. K. Suhr, and H. G. Jung, "Application requirement-driven automatic isp parameter tuning for a rear view monitoring camera," IEEE Access, 2021.

[22] S. Subedi and H. Tang, "Development of a multiple-camera 3d vehicle tracking system for traffic data collection at intersections," IET Intelligent Transport Systems, vol. 13, no. 4, pp. 614-621, 2018.

[23] B. Robinson, D. Langford, J. Jetton, L. Cannan, K. Patterson, R. Diltz, and W. English, "Real-time object detection and geolocation using 3d calibrated camera/lidar pair," in Autonomous Systems: Sensors, Processing, and Security for Vehicles and Infrastructure 2021, vol. 11748. International Society for Optics and Photonics, 2021, p. 117480A.

[24] Z. Liu, D. Lu, W. Qian, K. Ren, J. Zhang, and L. Xu, "Vision-based inter-vehicle distance estimation for driver alarm system," IET Intelligent Transport Systems, vol. 13, no. 6, pp. 927-932, 2018.

[25] M. Aki, T. Rojanaarpa, K. Nakano, Y. Suda, N. Takasuka, T. Isogai, and T. Kawai, "Road surface recognition using laser radar for automatic platooning," IEEE Transactions on Intelligent Transportation Systems, vol. 17 , no. 10 , pp. $2800-2810,2016$.

[26] D. Song, G.-M. Tian, and J. Liu, "Real-time localization measure and perception detection using multi-sensor fusion for automated guided vehicles," in 2021 40th Chinese Control Conference (CCC). IEEE, 2021, pp. 3219-3224.

[27] Y. Yu, J. Li, H. Guan, C. Wang, and C. Wen, "Bag of contextual-visual words for road scene object detection from mobile laser scanning data," IEEE Transactions on Intelligent Transportation Systems, vol. 17, no. 12, pp. 3391-3406, 2016.

[28] J. Zhao, H. Xu, J. Wu, Y. Zheng, and H. Liu, "Trajectory tracking and prediction of pedestrian's crossing intention using roadside lidar," IET Intelligent Transport Systems, vol. 13, no. 5, pp. 789-795, 2019.

[29] J. A. Leñero-Bardallo, J.-M. Guerrero-Rodriguez, R. Carmona-Galán, and A. Rodriguez-Vazquez, "On the analysis and detection of flames with an asynchronous spiking image sensor," IEEE Sensors Journal, vol. 18, no. 16, pp. 6588-6595, 2018.

[30] Y. Liang, R. Ding, and Z. Zhu, "A 9.1 enob 200ms/s asynchronous sar adc with hybrid single-ended/differential dac in 55-nm cmos for image sensing signals," IEEE Sensors Journal, vol. 18, no. 17, pp. 7130-7140, 2018.

[31] D. L. Stone, G. Shah, and Y. Motai, "Direct spherical calibration of omnidirectional far infrared camera system," IEEE Sensors Journal, vol. 19, no. 13, pp. 5285-5298, 2019.

[32] R. Saket, W. C. S. Kaushik, and C. G. Singh, "Biorhythmic analysis to prevent aviation accidents," in Innovations in Defence Support Systems2. Springer, 2011, pp. 207-240.
[33] J. Reitman, "Achieving employee safety-lessons from the railroad," IEEE Technology and Society Magazine, vol. 12, no. 1, pp. 27-32, 1993.

[34] S. Mockel, F. Scherer, and P. F. Schuster, "Multi-sensor obstacle detection on railway tracks," in IEEE IV2003 Intelligent Vehicles Symposium. Proceedings (Cat. No. 03TH8683). IEEE, 2003, pp. 42-46.

[35] J. J. García, J. Ureña, A. Hernandez, M. Mazo, J. A. Jiménez, F. J. Álvarez, C. De Marziani, A. Jiménez, M. J. Díaz, C. Losada et al., "Efficient multisensory barrier for obstacle detection on railways," IEEE Transactions on intelligent transportation systems, vol. 11, no. 3, pp. 702-713, 2010.

[36] J. J. García, A. Hernandez, J. Ureña, and E. Garcia, "Fpga-based architecture for a multisensory barrier to enhance railway safety," IEEE Transactions on Instrumentation and Measurement, vol. 65, no. 6, pp. 1352-1363, 2016.

[37] Q. Li and S. Ren, "A real-time visual inspection system for discrete surface defects of rail heads," IEEE Transactions on Instrumentation and Measurement, vol. 61, no. 8, pp. 2189-2199, 2012.

[38] S. S. Beauchemin, M. A. Bauer, T. Kowsari, and J. Cho, "Portable and scalable vision-based vehicular instrumentation for the analysis of driver intentionality," IEEE Transactions on Instrumentation and Measurement, vol. 61, no. 2, pp. 391-401, 2011.

[39] D. E. Brown, "Text mining the contributors to rail accidents," IEEE Transactions on Intelligent Transportation Systems, vol. 17, no. 2, pp. 346-355, 2015.

[40] H. Salmane, L. Khoudour, and Y. Ruichek, "A video-analysis-based railway-road safety system for detecting hazard situations at level crossings," IEEE transactions on intelligent transportation systems, vol. 16, no. 2, pp. 596-609, 2015.

[41] M. Macucci, S. Di Pascoli, P. Marconcini, and B. Tellini, "Derailment detection and data collection in freight trains, based on a wireless sensor network," IEEE Transactions on Instrumentation and Measurement, vol. 65, no. 9, pp. 1977-1987, 2016.

[42] M. SeyyedEsfahlan, E. Öztürk, M. Kaynak, and I. Tekin, "77-ghz fourelement phased-array radar receiver front end," IEEE Transactions on Components, Packaging and Manufacturing Technology, vol. 6, no. 8, pp. 1162-1173, 2016.

[43] D. Monnin, A. L. Schneider, F. Christnacher, and Y. Lutz, "A 3d outdoor scene scanner based on a night-vision range-gated active imaging system," in Third International Symposium on 3D Data Processing, Visualization, and Transmission (3DPVT'06). Ieee, 2006, pp. 938-945.

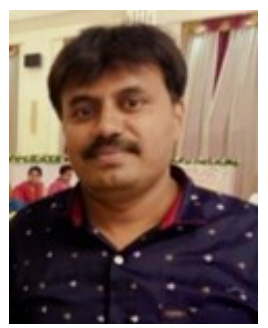

Anand Kumar Kyatsandra is a Senior Technical Officer in the Division of the Electrical Engineering, CSIR-National Aerospace Laboratories, Bangalore, Karnataka, India. Previously, he was an Assistant Engineer at University Works Department, IIT (BHU), Varanasi, UP, India. He has received his Ph.D. degree in Electrical Engineering from IIT (BHU), Varanasi, UP, India in 2019. He has more than twenty years of field experience in the Electrical and Electronics Engineering areas. He is the author/co-author of approximately 12 research papers in the fields of renewable energy systems and Reliability Engineering. His research interests include social mission related to special technologies of electrical and electronics engineering, power system reliability and renewable energy systems. 


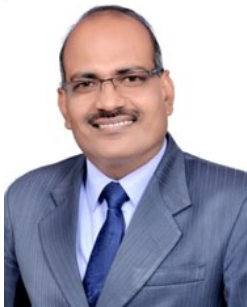

R. K. Saket is currently a Professor with the Department of Electrical Engineering, IIT (BHU), Varanasi, Uttar Pradesh, India. He has more than twenty years of academic and research experience. $\mathrm{He}$ is the author/co-author of approximately 125 scientific articles, book chapters and research papers in prestigious international journals and conference proceedings. He has received many awards, honours and recognitions for his academic \& research contributions. $\mathrm{He}$ is a Fellow of the Institution of Engineers (India), Senior Member of the IEEE (USA); Member of the IET (UK), and life member of the ISTE (India). He is an Associate Editor of the IET Renewable Power Generation (UK), editorial board member of the Journal of Electrical Systems (France); and Engineering, Technology and Applied Science Research (Greece). He is an expert reviewer of the IEEE Systems Journal, IEEE Access, IET Generation, Transmission \& Distribution, IET Renewable Power Generation, Electric Power Components \& Systems, Renewable \& Sustainable Energy Reviews, Energy Elsevier, Electric Power System Research, and International Journal of Electrical Power and Energy Systems. His research interests include power system reliability, electrical machines and drives, reliability aspects of energy systems, renewable power generation, and renewable sources of electrical energy.

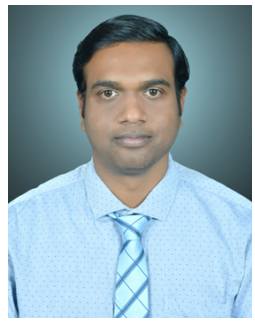

Sachin Kumar received his B. Tech. Degree in Electrical Engineering from Harcourt Butler Technological University (formerly Harcourt Butler Technological Institute), Kanpur (UP) India in 2008 and M. Tech. Degree with a specialization in Power System Engineering from Indian Institute of Technology Kharagpur (WB) India in 2010 . He is working as an Assistant Professor in the Department of Electrical Engineering, Govind Ballabh Pant Institute of Engineering \& Technology, Ghurdauri, Pauri Garhwal (UK) India. Currently, he is a doctoral research scholar in the Department of Electrical Engineering, IIT (BHU); Varanasi (UP) India. He has published many research papers in the indexed international journals and book chapters in prestigious handbooks. His field of interest includes reliability engineering, power system reliability, renewable energy systems, and green energy conversion systems.

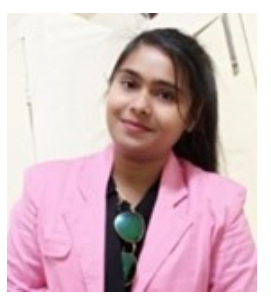

Kumari Sarita was born in Dhanbad, Jharkhand, India. She received her B.Tech. degree in Electrical and Electronics Engineering from G.G.S.E.S.T.C., Bokaro, Jharkhand, India, in 2017, and M. Tech. degree in Electrical Engineering with a specialization in Power Systems from BIT Sindri, Dhanbad, Jharkhand, India in 2019. She is currently pursuing $\mathrm{PhD}$ in Electrical Machines and Drives from the department of Electrical Engineering, Indian Institute of Technology (BHU), Varanasi, Uttar Pradesh, India. Her current research interest includes renewable energy resources, predictive maintenance of electrical equipment, and power system reliability.

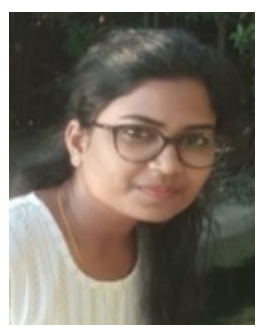

Aanchal Singh S. Vardhan received her B. Tech. Degree in Electrical Engineering from Sam Higginbottom University of Agriculture, Technology and Sciences, Allahabad (Uttar Pradesh) India in 2019. Currently, she is pursuing her M.E. Degree in Electrical Engineering with specialization in Power Electronics from Shri G.S. Institute of Technology and Science, Indore (Madhya Pradesh) India affiliated to Rajiv Gandhi University of Technology, Bhopal (Madhya Pradesh) India. Her innovative research work entitled Movable Solar Power Generator has been nominated for prestigious GYTI Award - 2020 at Rashtrapati Bhavan, New Delhi, India. She has published many research papers in reputed international journals and conference proceedings. She is reviewer of the IEEE access. Her research interest includes renewable energy, wind energy conversion systems, DFIG controller design, design of synchronous generator, and modern aspects of power electronics.

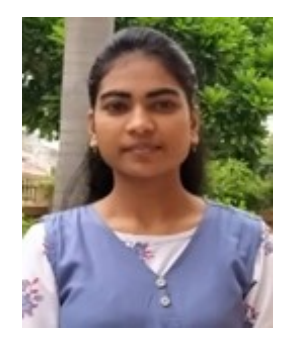

Akanksha Singh S. Vardhan received her B. Tech. Degree in Electrical Engineering from Sam Higginbottom University of Agriculture, Technology and Sciences, Allahabad (Uttar Pradesh) India in 2019. Currently, she is pursuing her M.E. Degree in Electrical Engineering with specialization in Power Electronics at Shri G.S. Institute of Technology and Science, Indore (Madhya Pradesh) India affiliated to Rajiv Gandhi University of Technology, Bhopal (Madhya Pradesh) India. Her innovative research work entitled "Movable Solar Power Generator" has been nominated for prestigious GYTI Award - 2020 at Rashtrapati Bhavan, New Delhi, India. She has published many research papers in reputed international journals and conference proceedings. Her research interest includes power electronics and drives, renewable energy technology, SEIG and DFIG controller design, synchronous generator modeling, reliability engineering, and green energy conversion systems. 